\title{
Micro Propagation of Several Potted Anthurium Accessions Using Spathe Explants
}

\author{
Kurniawan Budiarto \\ Indonesian Ornamental Crops Research Institute \\ JI. Raya Ciherang-Pacet, PO. Box. 8 SDL, Cianjur, West Java, Indonesia 43253 \\ Diterima 18-06-2008_Disetujui 26-09-2008
}

\begin{abstract}
The introduction of new varieties and production system of anthuriums has faced some problems due to the low multiplication rates in conventional vegetative and genotypic alteration problem in reproductive propagation. Since then, in vitro propagation technique became important to be investigated. The research was carried out from September 2006 to August 2007 at the Indonesian Ornamental Crops Research Institute. A complete factorial experiment was designed to accomplish two chronological in vitro activities. The first step dealt with different incubation sites, i.e. dark and light conditions for callus induction of three potted anthurium accessions, namely clone no. SM. 001, cv. Alphine and cv. Bonito. The best callus obtained from the incubation treatment were then, transferred into defined media with different formulations to get free-callus plantlets in the second steps. The results showed that more progressive callus development from spathe explant was detected on the media of modified Nitsch and Nitsch $+1 \mathrm{mg} / \mathrm{l} 2, \mathrm{D}+1 \mathrm{mg} / \mathrm{K} \mathrm{Kin}+1 \mathrm{mg} / \mathrm{l} \mathrm{BA}$ stored at dark after 60 days incubation. After 45 days transferring the callus in the same media on light conditions, torpedo-shaped callus was detected. Complete planlets were obtained after 75 days reculturing the buds in Nitsch and Nitsch medium containing 2,4 D with various BA concentrations. Clone SM. 001 and cv. Bonito showed higher number of visible shoot and root developments compared to cv. Alphine. In general, better shoot and root developments and higher planlets survived after acclimatization were observed on the BA concentrations of 2 and $3 \mathrm{mg} / \mathrm{l}$.
\end{abstract}

Keywords : Anthurium andreanum, accessions, spathe explant, planlet, in vitro.

\section{INTRODUCTION}

Anthurium (Anthurium andreanum) is one of important potted and cut flower ornamentals in the world. Long life span of flower with variation of the colors and simultaneous growth of flowers combined with a compact plant architecture growth were known to be the distinct characteristic of this commodity compared to other potted ornamentals. The conventional propagation in the field has faced some constraints due to the slow growth of the young buds and disease attacks. Potted anthurium is usually vegetatively propagated by young bud divisions. After the young bud was replanted, the successive growth of plants in almost all cases was not uniform and unpredictable. The involvement Erwinia carotovoraand Dasheen Mosaic Virus (DMV) was also known to have impacts on the growth and survivals rates of the planted young buds. These low propagation rates hinder the introduction of new varieties or virus-free plants.

Telp/Fax: (0263) 512607/514138

Email:bud1arto@yahoo.com
To accelerate the incoming varieties to be released, the proper propagation of selected clones should be established to preserve sufficient amount of healthy seedlings. In other crops, in vitro propagation has shown to be an excellent tool for rapid upbuilding for marketable quantities of plants with selected characters. These method guaranteed the identical reproduction of the parents tested and selected, and prevented genotypic alteration which would occur after the generative multiplication (Chen et al, 2002).

The successful in vitro propagation of cut flower anthurium using young leaf explant to reduce contamination and oxidative browning of explants after culture inspiring the use of whirled and young spathe was also possible as source of explant. The steps of culture followed the methods of Budiarto and Handayati (2007). The first step was the establishment of aseptic explant culture to encourage cell division for callus formation. Modification of nutrient and vitamins, supplemental hormones and dark condition were usually applied to facilitate this meristematic activity (Chand et al, 1999). The next step was then, induction of the multiplied cells to undergo further differentiation and 
proliferation to form shoot and root until the complete planlets were obtained. In this period, the existence of light was usually needed to serve the organogenesis process (Martin et al, 2001). In this paper, the study of in vitro propagation in three accessions of anthurium using spathe explant was described. The presence of light for callus induction and hormone modification for further callus proliferation were investigated.

\section{MATERIALS AND METHODS}

The research was conducted in the tissue culture laboratory at the Indonesian Ornamental Crops Research Institute from September 2006 to August 2007. Two experimental series were designed in complete factorials with 10 replications in each study. The first experiment dealt with the influence of incubation sites i.e. dark and light conditions on the callus formation of inoculated spathe explants of three anthurium accessions, i.e. clone no. SM. 001, cv. Alphine and cv. Bonito. While, the second was carried out to find out the effects of various BA concentration on shoot and root formation and survival rate of planlets after acclimatization.

Plant material and explant preparation. Anthurium clone no. SM. 001 was one of selected promising clones resulted from breeding activities. While the plant materials of $\mathrm{cv}$. Alphine and cv. Bonito were collected from the commercial nursery. The collected plants of the three accessions were replanted into $15 \mathrm{~cm}$ pots. The plants were then, placed into green house for further maintenance for 8 weeks. Twice a week foliar applications of nitrogen fertilizer were applied to promote new leaf development. After at least 3-4 complete leaves were formed, single shot of 200 ppm of $\mathrm{GA}_{3}$ were given through foliar application for flower induction. Each plant was sprayed for about 40 $\mathrm{ml}$ of emulsion which was previously added with wetting agent of $0.05 \%$ Tween 20 .

After 8-10 weeks, the flowers were emerged. The whirled and young spathe of flower was then, served as the source of explants. The explants were collected by cutting the spathe and disinfected in $0.1 \%$ sodium hypochlorite with 2 drops of wetting agent (Tween 20/ $100 \mathrm{ml}$ ) for 2 minutes. The spathes were then, sterilized with $80 \%$ ethanol for 1 minute and rinsed twice with autoclaved sterile water.
Sterile explant culture establishment and callus induction. After quick drying with sterile papers, the spathes were cut into explant pieces with the size of $2 \times 2 \mathrm{~cm}$. Each explant piece was inoculated into free hormone media for 7 days to ensure no contamination existed in the cultures. The explants were then, transferred into the modified Nitsch and Nitsch supplemented with $1 \mathrm{mg} / \mathrm{l}$ 2,4 D + $1 \mathrm{mg} / \mathrm{l}$ Kinetin $+1 \mathrm{mg} / \mathrm{BA}$ media and stored in the treatment sites (dark and light conditions) under $16-18^{\circ} \mathrm{C}$ daily temperature. The observation of callus development was conducted after 60 days incubation in both sites.

Shoot-root development and planlets formation. The best callus formations derived from the first experiment were used for further shoot proliferation and root induction. The callus were deflasked into the same media and transferred into light condition with 16 $\mathrm{h}$ long day. After 45 days incubation, the callus were sliced into media treatments comprised of Nitsch and Nitsch + $1 \mathrm{mg} / \mathrm{l} 2,4 \mathrm{D}+(1,2$, and 3$) \mathrm{mg} / \mathrm{l} B A$ and incubated in $16 \mathrm{~h}$ long day. The observation of the complete planlets were conducted after 75 days from subculturing the plantlet into media with BA treatments, and the planlets were then, transferred outside for acclimatization.

\section{RESULT AND DISCUSSION}

Callus induction and bud formation. The callus formations of the three Anthurium accessions were influenced by the site of incubation. However, there is no interrelation among the three anthurium accessions can be observed on the specific incubation site. Table 1 showed that explant cultures incubated in the dark condition had better callus development than those stored with the presence of light after 60 days incubation. The globose callus as indication of cell multiplications were detected on the spathe explant margin as presented in Figure 1.

More excessive callus development detected on spathe explants stored in dark site inferred that cell multiplication was highly influenced by the presence of light. The cells were presumably able to multiply more rapidly in the absent of light. In contrast, with the presence of light, cell multiplications were suppressed. These indicated that the cell mitotic activities were not only affected by the composition of the related 

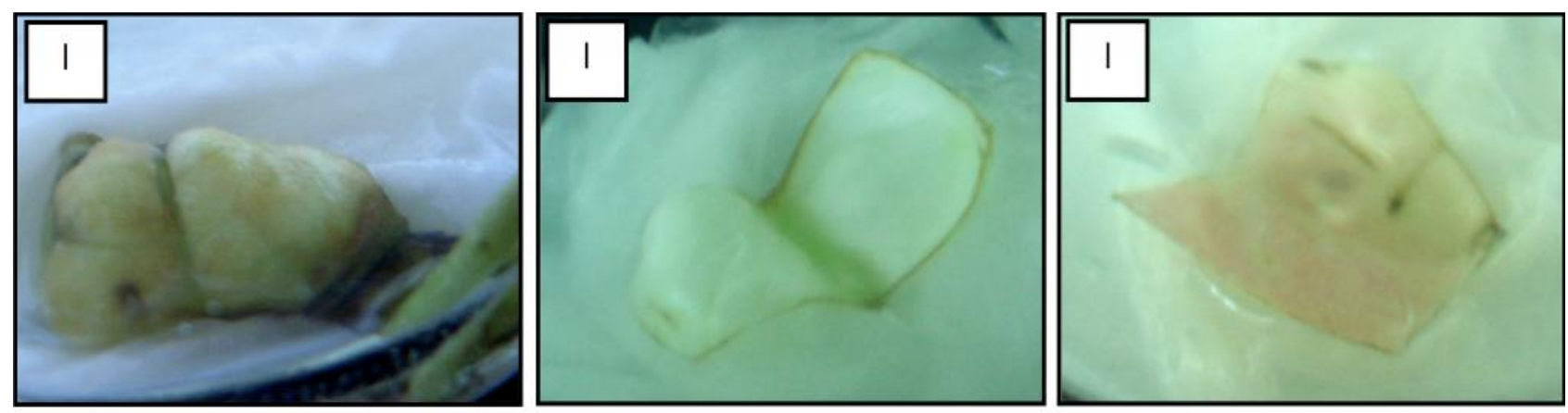

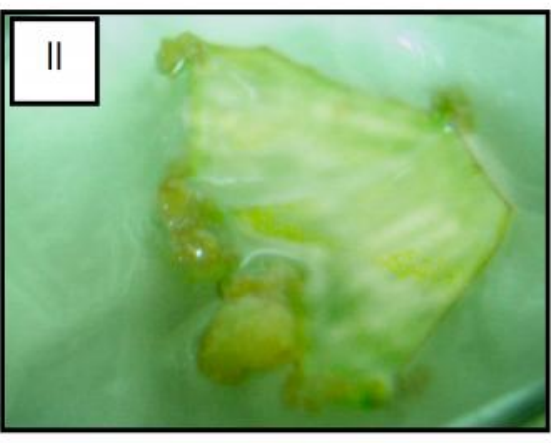

(a)

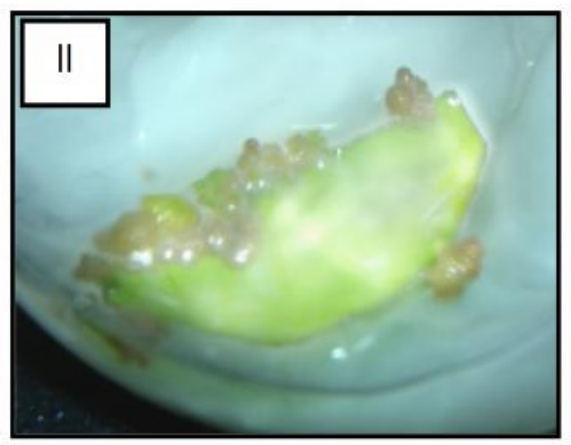

(b)

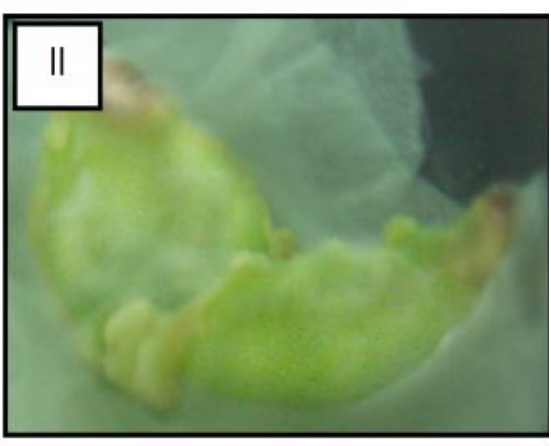

(c)

Figure 1. Spathe explant culture of three potted anthurium accessions; (a) clone SM. 001, (b) cv. Alphine and (c) cv. Bonito on the different incubation sites, (i) light and (ii) dark conditions after 60 days incubation.

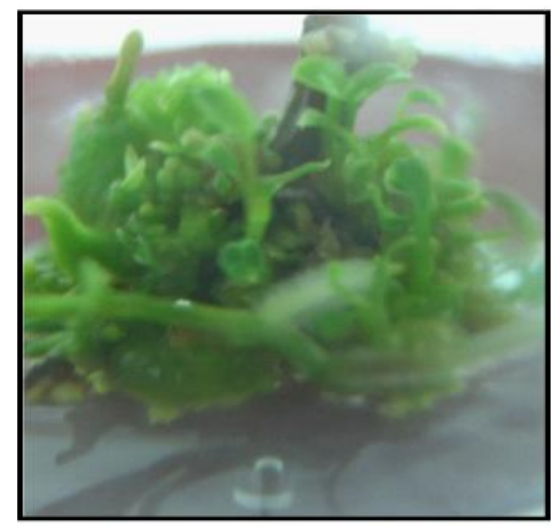

(a)

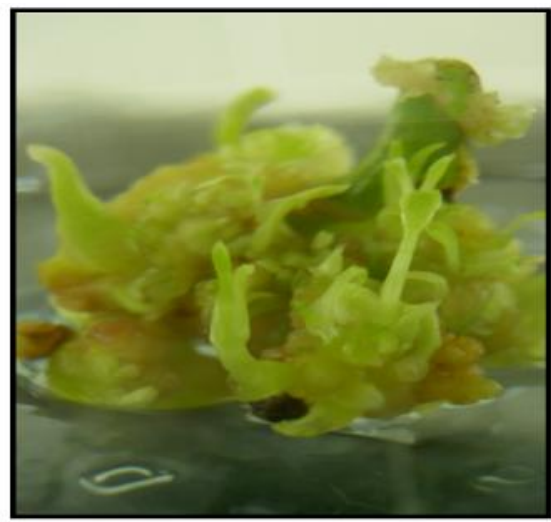

(b)

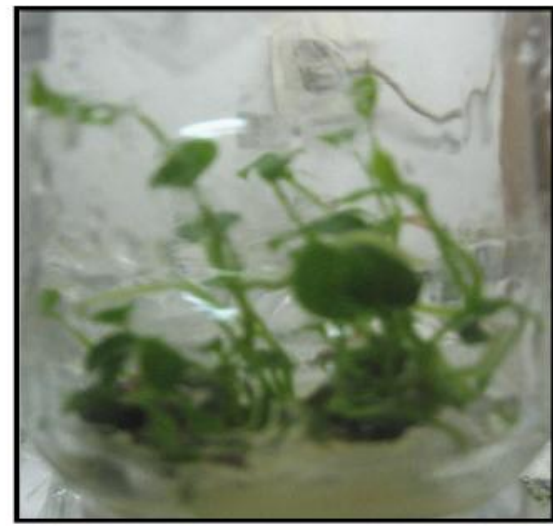

(c)

Figure 2. Shoot proliferation and more buds development from the transferred callus of three potted anthurium accession planlets; (a) clone SM. 001, (b) cv. Alphine and (c) cv. Bonito into the same media after 45 days light incubation.

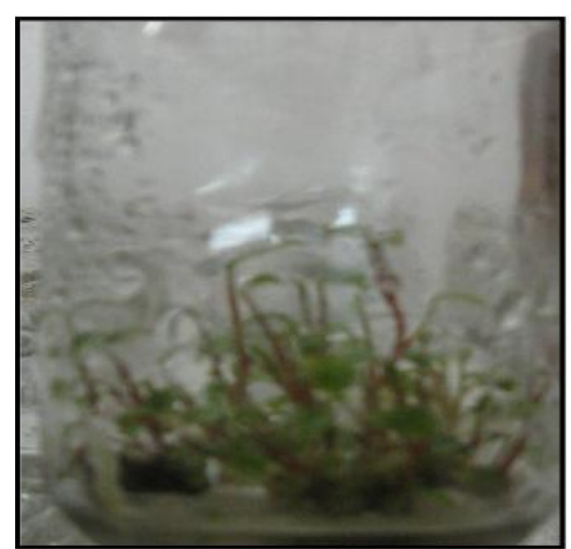

(a)

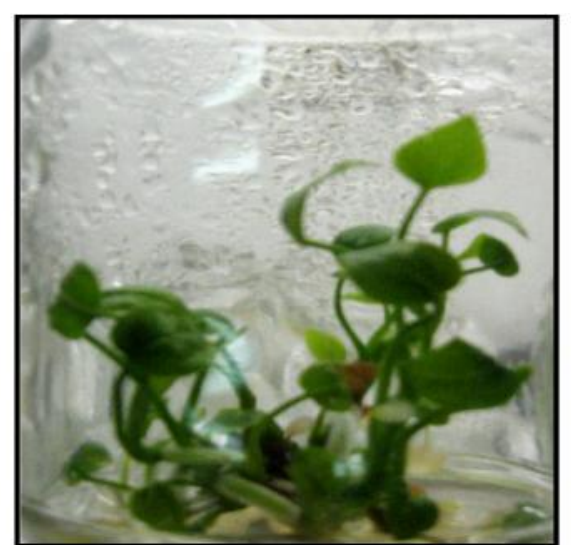

(b)

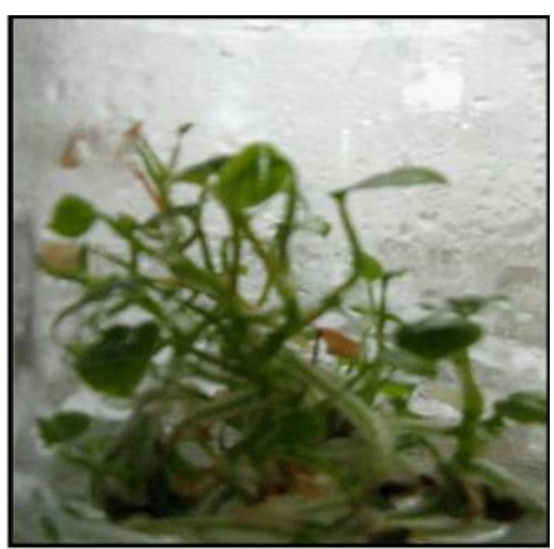

(c)

Figure 3. Complete planlets of three potted anthurium accessions; (a) clone no. SM. 001, (b) cv. Alphine and (c) cv. Bonito on Nitsch and Nitsch media containing $3 \mathrm{mg} / \mathrm{l} \mathrm{BA}$ after 75 days subculture. 
Table 1. Spathe culture after 60 days incubation in dark and light conditions in modified Nitsch and Nitsch medium supplemented with $1 \mathrm{mg} / \mathrm{l} 2,4 \mathrm{D}+1 \mathrm{mg} / \mathrm{l} \mathrm{Kinetin}+1 \mathrm{mg} /$ I BA

\begin{tabular}{|c|c|c|c|}
\hline \multirow[b]{2}{*}{$\begin{array}{l}\text { Incubation } \\
\text { sites }\end{array}$} & \multicolumn{3}{|c|}{ Explants development after 60 days incubation } \\
\hline & $\begin{array}{c}\text { Callus } \\
\text { development }\end{array}$ & $\begin{array}{l}\text { Color of the } \\
\text { newly } \\
\text { developed } \\
\text { cells }\end{array}$ & $\begin{array}{c}\text { Size changes } \\
\text { from the } \\
\text { originals }\end{array}$ \\
\hline Light & - & $\begin{array}{c}\text { paler from the } \\
\text { original }\end{array}$ & - \\
\hline Dark & + & whitish green & + \\
\hline
\end{tabular}

Remarks : (+) = significant growth/changes observed $(-)=$ retarded $/$ no significant growth

Table 2. Average number of visible shoots and roots of potted anthurium accession planlets after 75 days incubation

\begin{tabular}{lcc}
\hline \multirow{2}{*}{$\begin{array}{c}\text { Anthurium } \\
\text { accessions }\end{array}$} & \multicolumn{2}{c}{$\begin{array}{c}\text { Planlet performances after 75 days } \\
\text { incubation }\end{array}$} \\
\cline { 2 - 3 } & $\begin{array}{c}\text { Number of visible } \\
\text { shoots }\end{array}$ & $\begin{array}{c}\text { Number of visible } \\
\text { roots }\end{array}$ \\
\hline $\begin{array}{l}\text { cv. Alphine } \\
\text { Clone no. }\end{array}$ & $7.82 \mathrm{a}$ & $8.13 \mathrm{a}$ \\
SM. 001 & $12.13 \mathrm{~b}$ & $11.72 \mathrm{~b}$ \\
cv. Bonito & $14.58 \mathrm{~b}$ & $10.71 \mathrm{~b}$ \\
\hline
\end{tabular}

") values followed by different letters in the same column differ significantly at LSD $5 \%$

hormones and the concentration of these hormones within the media (Rosario \& Valenzuela 1998). In some cases, the existence of physical environment such as the light, might also have effected accumulation of particular hormone eg. auxin on the meristematic sites (Keunhle \& Sugii 1991). The alteration of one or more hormones concentration then contributed to the hormonal imbalance and finally decreased the meristematic activities level on the explants incubated in light condition. This situation was true, since up to 80 days culture only a little cells growth was detected on these explants. The spathe explant was swallowed, but only few white and transparent callus appeared in the leaf margin (figures not presented).

In contrast with these situation, the callus from the explants incubated in dark condition continued to grow and the appearance of torpedo callus (initial bud) was detected in 60 days (Figure 1). Forty five days after transferring the callus in the same media and incubating them in light condition, the buds showed more advance growth with initial leaves appearance (Figure 2). Rosario \& Lapitan (1981), reported that the
Table 3. Average number of shoots and roots of potted anthurium planlets on various BA concentrations after 75 days subculture and survival rate of acclimated planlets.

\begin{tabular}{|c|c|c|c|}
\hline \multirow[b]{2}{*}{$\begin{array}{c}\text { BA concentrations } \\
(\mathrm{mg} / \mathrm{l})\end{array}$} & \multicolumn{2}{|c|}{$\begin{array}{l}\text { Planlet performances } \\
\text { after } 60 \text { days incubation }\end{array}$} & \multirow{2}{*}{$\begin{array}{c}\text { Survival rate } \\
\text { after } \\
\text { acclimatization } \\
(\%)\end{array}$} \\
\hline & $\begin{array}{c}\text { Number of } \\
\text { visible } \\
\text { shoots }\end{array}$ & $\begin{array}{l}\text { Number } \\
\text { of visible } \\
\text { roots }\end{array}$ & \\
\hline 1 & $8.13 \mathrm{a}$ & $6.48 \quad \mathrm{a}$ & 90 \\
\hline 2 & $10.74 \mathrm{~b}$ & $12.53 \mathrm{~b}$ & 100 \\
\hline 3 & $13.27 b$ & $9.34 \mathrm{~b}$ & 100 \\
\hline
\end{tabular}

") values followed by different letters in the same column differ significantly at LSD $5 \%$

presence of light had different effect on the cell division and differentiation. The maximum callus growth and embryogenesis might occur and enhance in dark condition. However, after the buds were formed, the presence of light was required for the further shoot proliferation and elongation.

Shoot and root induction. After 45 days incubating the cultures in light condition, the buds were then transferred for further shoot and root formation. The shoot and root inductions were conducted by subculturing the buds to defined medium. The Nitsch and Nitsch medium containing 2,4 D with various concentration of BA (1,2 and $3 \mathrm{mg} / \mathrm{l})$ were served for the treatment. One bud with the size of approximately $0,5 \mathrm{~cm}$ was inoculated in one culture flask per replication for observing the shoot and root development.

Analysis of variances on each factor indicated that there was no interaction detected between anthurium accessions with BA concentrations. After 75 days incubation in light condition the complete planlets were obtained and the number of shoot and root formed in each treatments were observed and presented in Table 2 and 3. Different number of visible shoots and roots were detected among the accessions tested. Planlet of clone no. SM. 001 and cv. Bonito showed the higher number of visible shoots and roots after 75 days subculture compared to cv. Alphine.

The lesser number of shoot and root observed in $\mathrm{cv}$. Alphine planlets indicated that the growth rate of this accession were less progressive to form shoot and root in the presence of BA under light condition compared to clone no. SM. 001 and cv. Bonito. These conditions were predictably connected with the genetic composition among the accessions tested. According 
to Martin et al, (2002), the growth characteristic among accessions was genotypicly indigenous. Such cultivars could show faster or slower shoot and root formation even in the same media during in vitro culture. The complete planlets of the three accessions of anthurium were presented in Figure 3.

The presence of BA also affected on the number of newly developed shoots and roots of planlets. Table 3 showed that number of shoots increased in line with the higher BA concentration in the media. The highest shoot formation was observed in Nitsch and Nitsch media supplemented with $3 \mathrm{mg} / \mathrm{BA}$, though the value was not significantly different with those in $2 \mathrm{mg} / \mathrm{l}$. The number of roots, however, was found highest in $2 \mathrm{mg} / \mathrm{l}$ BA with slight decrease compared to those in the media of $3 \mathrm{mg} / \mathrm{l} \mathrm{BA}$. While, the least shoot and root formations were observed in the media containing $1 \mathrm{mg} / \mathrm{l} \mathrm{BA}$.

Further organogenesis process, reflected from higher shoot and root formation on the planlets given with 2 and $3 \mathrm{mg} / \mathrm{BA}$, indicated that the process of shoot and root development was accelerated with the increase of BA concentration. The negligible differences between the 2 and $3 \mathrm{mg} / \mathrm{l} \mathrm{BA}$ also inferred the light-BA interaction in the certain range was influenced by the endogen hormonal balance and the maximum response of the cells to the BA concentration (Villalobos et al, 1984). These findings implied that BA concentration ranging from 2 to $3 \mathrm{mg} / \mathrm{l}$ was specific for these three anthurium accessions in Nitsch and Nitsch medium for optimal shoot and root development. The optimal growth of shoot and root then, might contributed to better adaptation and higher survival rate of planlets during acclimatization (Table 3).

\section{CONCLUSIONS}

Micro propagation of three potted anthurium accessions using spathe explants was successfully conducted. Using modified Nitsch and Nitsch medium supplemented with 2,4-D, Kinetin and BA, better callus development were observed in dark incubation. Buds development was accelerated after transferring the callus in the same media to light condition. In the presence of BA and light, clone no. SM. 001 and cv. Bonito showed higher shoot and root formations than cv. Alphine after 75 days culture. Complete planlets with shoot and root formation were obtained after transplanted the buds in Nitsch and Nitsch medium containing $1 \mathrm{mg} / \mathrm{l}$ 2,4-D, $1 \mathrm{mg} / \mathrm{l} \mathrm{Kinetin}$ with various BA concentrations. The higher shoot and root development and the survival rate of planlets after acclimatization were observed in the BA concentrations of 2 and $3 \mathrm{mg} /$ I with insignificant differences.

\section{ACKNOWLEDGEMENT}

The author would like to thank to Teresita L. Rosario, PhD (Ornamental Crops Division- Department of Horticulture, University of The Philippines Los Banos) for her valuable assistance, criticms and suggestions during the conduct of the research and preparation of the article.

\section{REFERENCES}

Budiarto, K. and W. Handayati. 2007. In vitro propagation of several anthurium accessions using leaf explants. AGRIVITA. 39 (3) : 261 - 268.

Chen, J., R. J. Henny and D. B. McConnell. 2002. Development of new foliage plant cultivars. Florida Agric. Exp. Sta. J. R08541: $1-7$.

Chand, H., M. N. Pearson and P. H. Lovell. 1999. Rapid vegetative multiplication in Colocasia esculenta (L.) Schott (taro). Plt Cell, Tissue, and Organ Cult. 55: 223 - 226.

Keunhle, A. R. and N. Sugii. 1991. Callus induction and plantle regeneration in tissue culture of Hawaiian anthurium. HortSci. 26 (7): 919 - 921.

Martin, S. P., C. A. Babisud and T. T. Sekioka. 2001 Micropropagation of white taro (Colocasia esculenta var esculenta) cv. Pikokea, Pololu, Nipopu, and Haukea. HortSci. 28: $543-545$.

Martin, K., P. Joseph, Dominic, M. Joseph, and V. J. Phillips 2002. Direct shoot regeneration from lamina explants of two commercial cut flowers cultivars of Anthurium andreanum Hort. In Vitro Cell. And Dev. Biol. 39 (5) : $24-28$.

Rosario, T. L. and L. A. Lapitan. 1981. Callus and plantlet formation of Anthurium andreanum Lind. Phil Agric. 64 (2) $197-202$.

Villalobos, V. M., D. W. M. Leung and T. A. Thorpe. 1984. Light-cytokinin interaction in shoot formation in cultured cotyledon explants of radiate pine. Physiol. Plant. 61: 497 . 504.

Valenzuela, M. G. 1998. In vitro culture of Anthurium andreanum L. 'Gloria Angara' (Araceae). The Phil. J. of Crop Sci. 23 : 78. 